\title{
Broadband Photodetectors Based on c-Axis Tilted Layered Cobalt Oxide Thin Films
}

\author{
Shufang Wang* and Guangsheng Fu \\ Hebei Key Lab of Optic-Electronic Information and Materials, Hebei University, Baoding
}

PR China

\section{Introduction}

Laser-induced voltage (LIV) effects in c-axis tilted thin films of $\mathrm{YBa}_{2} \mathrm{Cu}_{3} \mathrm{O}_{7-\delta}(\mathrm{YBCO})$ and $\mathrm{La}_{1-\mathrm{x}} \mathrm{Ca}_{x} \mathrm{MnO}_{3}$ (LCMO) have been extensively studied in the past decades due to their potential applications in photodetectors [1-9]. Compared to the commonly used photodiodes-based photodetectors, this new type of photodetectors has the advantage of broad spectrum response ranging from ultra-violet (UV) to infrared (IR). Other advantages of this type of detectors consist in that they can be operated without cryogenic cooling and bias voltage.

The origin of the LIV signal was explained as result of the transverse thermoelectric effect which becomes effective when the $c$ axis of YBCO or LCMO films are tilted by an angle $\alpha$ with respect to the film surface normal [8]. The induced voltage can be quantitatively described by the equation

$$
U=\frac{l}{2 d} \sin (2 \alpha) \Delta S \Delta T
$$

Where $\Delta \mathrm{T}$ is the temperature difference between the top and bottom of the film, which is generated by heating the film surface due to the absorption of the incident laser radiation; $\Delta \mathrm{S}=\mathrm{S}_{\mathrm{ab}}-\mathrm{S}_{\mathrm{c}}$ is the difference of the seebeck coefficient in the $a b$-plane and along the $c$-axis of the film; $\alpha$ is the tilted angle of the film with respect to the surface normal; $d$ is the thickness of the tilted film and $\imath$ is the laser spot diameter [1]. According to this equation, searching for materials having large anisotropy in seebeck coefficient, that is large $\Delta S$, is a key factor for developing this new type photodetectors.

Recently, layered cobalt oxides including $\mathrm{Na}_{x} \mathrm{CoO}_{2}, \mathrm{Ca}_{3} \mathrm{Co}_{4} \mathrm{O}_{9}, \mathrm{Bi}_{2} \mathrm{Sr}_{2} \mathrm{Co}_{2} \mathrm{O}_{\mathrm{y}}$ and etc. have attracted great attention as promising thermoelectric materials due to their good thermoelectric performance as well as the good thermal stability, lack of sensitivity to the air and non-toxicity [10-14]. The crystal structure of these cobalt oxides consists of the conducting $\mathrm{CoO}_{2}$ layer and the insulating $\mathrm{Na}, \mathrm{Ca}_{2} \mathrm{CoO}_{3}$ or $\mathrm{Bi}_{2} \mathrm{Sr}_{2} \mathrm{O}_{4}$ layer, which are alternately stacked along the $c$-axis. This layered structure results in a large anisotropy of the

${ }^{*}$ Corresponding Author 
seebeck coefficient in the ab-plane and along the c-axis of the film, realizing $\Delta S=S_{\mathrm{ab}}-S_{\mathrm{c}}$ of tens of $\mu \mathrm{V} / \mathrm{K}$, which is about several times larger than that of $\mathrm{YBCO}(\sim 10 \mu \mathrm{V} / \mathrm{K})$ and hundreds times larger than that of $\operatorname{LCMO}(\sim 0.22 \mu \mathrm{V} / \mathrm{K})[3,4]$. This fact indicates the layered cobalt oxides might have potential applications in the field of high-sensitive broadband photodetectors. In this chapter, we present our investigation of LIV effects in caxis tilted cobalt oxide thin films $\left(\mathrm{Na}_{x} \mathrm{CoO}_{2}, \mathrm{Ca}_{3} \mathrm{Co}_{4} \mathrm{O}_{9}\right.$ and $\left.\mathrm{Bi}_{2} \mathrm{Sr}_{2} \mathrm{Co}_{2} \mathrm{O}_{y}\right)$ with different pulsed laser sources with wavelength ranging from UV to NIR. The open-circuit voltage signals were detected in these films when their surfaces were irradiated by the laser light. The results demonstrate that the $c$-axis tilted cobalt oxide thin films have great potential applications in the broadband photodetectors.

\section{Sample preparation and LIV measurements}

\subsection{Fabrication of $c$-aixs tilted $\mathrm{Na}_{\mathrm{x}} \mathrm{CoO}_{2}, \mathrm{Ca}_{3} \mathrm{Co}_{4} \mathrm{O}_{9}$ and $\mathrm{Bi}_{2} \mathrm{Sr}_{2} \mathrm{Co}_{2} \mathrm{O}_{\mathrm{y}}$ thin films}

The $c$-axis inclined $\mathrm{Na}_{x} \mathrm{CoO}_{2}$ thin film was obtained by epitaxially growing a layer of $\mathrm{Na}_{x} \mathrm{CoO}_{2}(x \sim 0.7)$ on a tilted $\mathrm{Al}_{2} \mathrm{O}_{3}$ (0001) single crystal substrate by topotaxially converting an epitaxial $\mathrm{CoO}$ film to $\mathrm{Na}_{x} \mathrm{CoO}_{2}$ with annealing in $\mathrm{Na}$ vapor. A CoO film was first epitaxial grown on the tilted $\mathrm{Al}_{2} \mathrm{O}_{3}$ (0001) by pulsed laser deposition. The $\mathrm{CoO}$ film was then sealed in an alumina crucible with $\mathrm{NaHCO}_{3}$ powder and heated to 700$750^{\circ} \mathrm{C}$ for $60 \mathrm{~min}$ to form the $\mathrm{Na}_{x} \mathrm{CoO}_{2}$ film. The $c$-axis tilted $\mathrm{Ca}_{3} \mathrm{Co}_{4} \mathrm{O}_{9}$ and $\mathrm{Bi}_{2} \mathrm{Sr}_{2} \mathrm{Co}_{2} \mathrm{O}_{\mathrm{y}}$ thin films can be grown on the tilted $\mathrm{LaAlO}_{3}(001)$ or $\mathrm{Al}_{2} \mathrm{O}_{3}$ (0001) substrates with the pulsed laser deposition (PLD) or chemical solution deposition (CSD) methods. The detailed PLD and CSD fabrication parameters can be found in Ref. 15-17. Transport measurements on these films reveal that they have the room temperature seebeck coefficient comparable to that of the single crystals, suggesting good quality of these films.

Fig. 1a-c presents the x-ray diffraction (XRD) $\theta-2 \theta$ scans of the $c$-axis tilted cobalt oxide thin films on $10^{\circ}$ tilted substrates. The offset angle $\omega$ is the angle between the $c$-axis direction and the substrate surface-normal direction and it is set as 10\% (See the inset of Fig. 1a). Apart from the substrate peak, all peaks in these patterns can be indexed to the $(00 l)$ diffractions of the corresponding layered cobalt oxides, indicating that phase-pure $c$-axis tilted $\mathrm{Na}_{x} \mathrm{CoO}_{2}$, $\mathrm{Ca}_{3} \mathrm{Co}_{4} \mathrm{O}_{9}$ and $\mathrm{Bi}_{2} \mathrm{Sr}_{2} \mathrm{Co}_{2} \mathrm{O}_{\mathrm{y}}$ thin films are obtained and the tilted angle is $10{ }^{\circ}$.

\subsection{LIV measurements}

Fig. 2 presents the schematic illustration of the LIV measurements. Two indium or gold electrodes with the diameter of $\sim 0.4 \mathrm{~mm}$ were symmetrically deposited on the film surface along the inclined direction and they were separated by $4 \mathrm{~mm}$. To prevent the generation of any electric contact effect, the electrodes were always kept in the dark. A $\mathrm{XeCl}$ excimer pulsed laser $\left(\lambda=308 \mathrm{~nm}, \mathrm{t}_{\mathrm{p}} \sim 20 \mathrm{~ns}\right)$ and an Nd:YAG pulsed laser $(\lambda=532$ and $1064 \mathrm{~nm}, \mathrm{t}_{\mathrm{p}} \sim 25 \mathrm{ps}$ ) were used as the light sources. The incident laser beam, adjusting to 2 $\mathrm{mm}$ in diameter using an aperture, was directed perpendicular to the film surface at the middle position between the two electrodes. The induced lateral voltage signals were recorded using a digital oscilloscope of $500 \mathrm{MHz}$ bandwidth terminated into $1 \mathrm{M} \Omega$ (Tektronix, TDS 3052). 

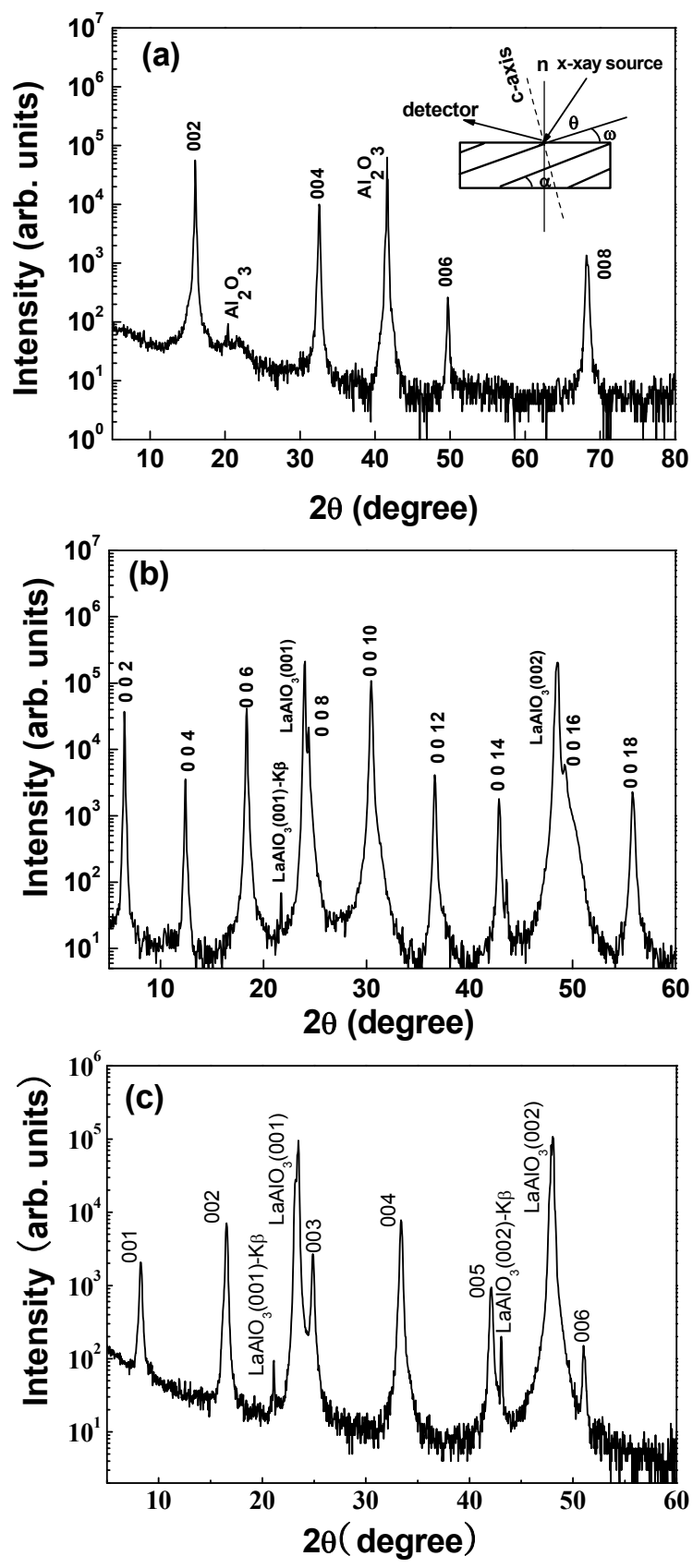

Fig. 1. XRD $\theta-2 \theta$ scans for the $c$-axis tilted (a) $\mathrm{Na}_{x} \mathrm{CoO}_{2}$, (b) $\mathrm{Bi}_{2} \mathrm{Sr}_{2} \mathrm{Co}_{2} \mathrm{O}_{y}$ and (c) $\mathrm{Ca}_{3} \mathrm{Co}_{4} \mathrm{O}_{9}$ thin film on $10^{\circ}$ tilted single crystal substrates. The inset of Fig. 1a is the sketch map of the XRD $\theta-2 \theta$ measurement and the offset angle $\omega$ is set as $10^{\circ}$. 


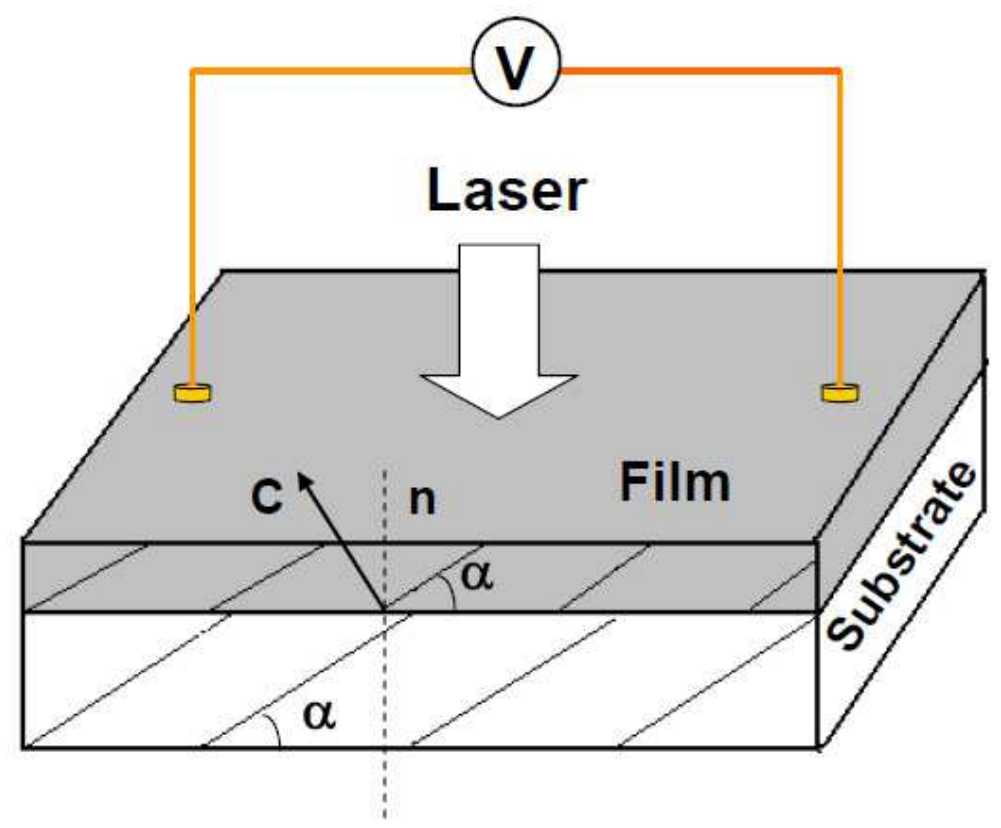

Fig. 2. Schematic illustration of the LIV measurements.

\section{Results and discussion}

\subsection{LIV response of the c-axis tilted $\mathrm{Bi}_{2} \mathrm{Sr}_{2} \mathrm{Co}_{2} \mathrm{O}_{\mathrm{y}}$ thin films to different laser pulses}

Fig. 3a-c presents the response of a $10^{\circ}$ tilted $\mathrm{Bi}_{2} \mathrm{Sr}_{2} \mathrm{Co}_{2} \mathrm{O}_{\mathrm{y}}$ thin film $(\sim 100 \mathrm{~nm})$ to the laser pulses of $308 \mathrm{~nm}, 532 \mathrm{~nm}$ and $1064 \mathrm{~nm}$, respectively. Large open-circuit signals with the response time in the order of several hundred nanoseconds are detected for these three wavelengths. The voltage responsivity is calculated to be about $440 \mathrm{mV} / \mathrm{mJ}, 348 \mathrm{mV} / \mathrm{mJ}$ and $65 \mathrm{mV} / \mathrm{mJ}$ for $308 \mathrm{~nm}, 532 \mathrm{~nm}$ and $1064 \mathrm{~nm}$ pulsed radiations respectively. The stronger LIV signals obtained for the UV $308 \mathrm{~nm}$ and visible $532 \mathrm{~nm}$ lasers than that for the NIR 1064 $\mathrm{nm}$ laser can be explained by considering the different optical absorption and penetration depth of the radiations with different wavelength in $\mathrm{Bi}_{2} \mathrm{Sr}_{2} \mathrm{Co}_{2} \mathrm{O}_{y}$ film. The higher absorption and smaller penetration depth of $308 \mathrm{~nm}$ and $532 \mathrm{~nm}$ radiation in comparison with these of the $1064 \mathrm{~nm}$ radiation lead to a larger $\Delta \mathrm{T}$ and thus a larger induced voltage.

To reduce the influence of the RC measurement circuit on the response time, a $2 \Omega$ load resistance is connected parallel with the tilted film while keeping other experimental conditions unchanged. As shown in Fig. 4, the rise time is dramatically decreased from $100 \mathrm{~ns}$ shown in Fig. 2a to about 6 ns and the FWHM is also decreased from $470 \mathrm{~ns}$ to be about $20 \mathrm{~ns}$. It should be mentioned here that the response time has a pronounced dependence on the pulse width of the incident lasers. The smaller pulse width usually leads to a faster response time. For example, the FWHM of the induced voltage signal is reduced to 1-2 ns when the same film is irradiated by the Nd:YAG picosecond laser pulse. The nanosecond-scale response of the tilted $\mathrm{Bi}_{2} \mathrm{Sr}_{2} \mathrm{Co}_{2} \mathrm{O}_{\mathrm{y}}$ thin film to different laser pulses ranging from UV to NIR reveals that it has a potential application in broadband photodetectors with fast response. 

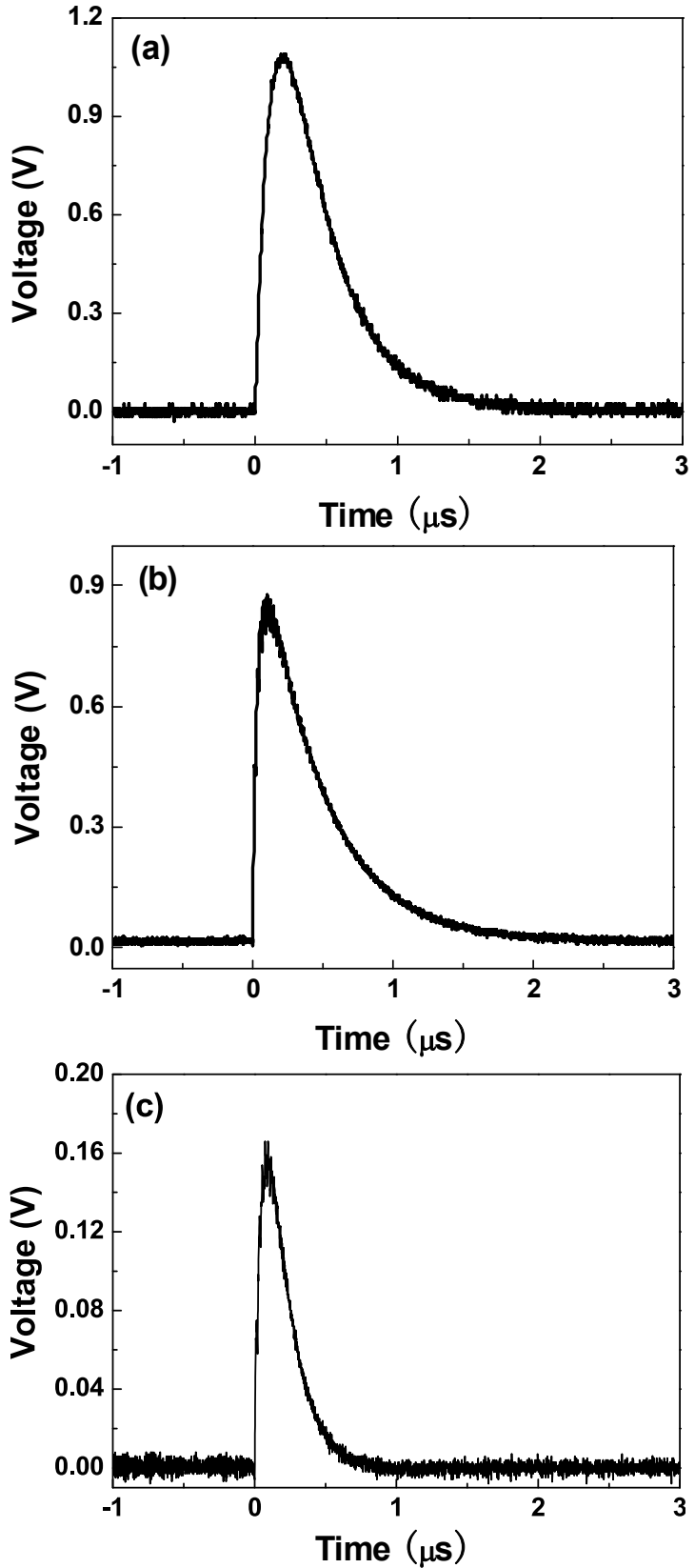

Fig. 3. LIV signals of a $10^{\circ} \mathrm{C}$-axis tilted $\mathrm{Bi}_{2} \mathrm{Sr}_{2} \mathrm{Co}_{2} \mathrm{O}_{\mathrm{y}}$ thin film $(\sim 100 \mathrm{~nm})$ when its surface is irradiated by the pulsed lasers with different wavelength of (a) $308 \mathrm{~nm}$, (b) $532 \mathrm{~nm}$ and (c) $1064 \mathrm{~nm}$. The input impedance of an oscilloscope is $1 \mathrm{M} \Omega$ and the laser energy on the sample is about $2.5 \mathrm{~mJ}$. 


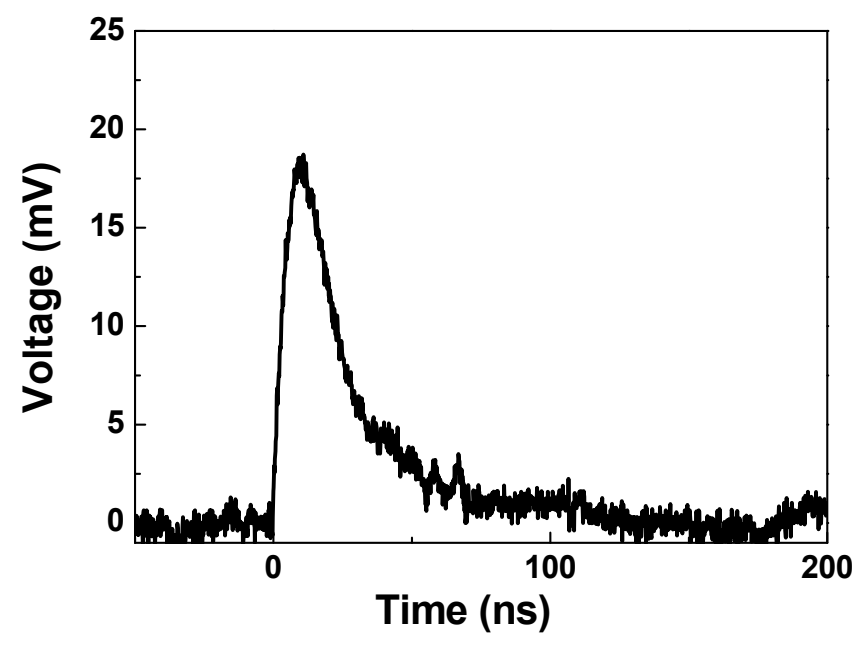

Fig. 4. LIV signal of a $10^{\circ} \mathrm{c}$-axis tilted $\mathrm{Bi}_{2} \mathrm{Sr}_{2} \mathrm{Co}_{2} \mathrm{O}_{\mathrm{y}}$ thin film under the $308 \mathrm{~nm}$ radiation after connecting a $2 \Omega$ load resistance in parallel with the tilted film.

\subsection{Dependence of the peak voltage of the LIV response on the laser energy, tilted angle and film thickness}

Fig. 5a shows the dependence of the peak value of the open-circuit voltage signal $\left(\mathrm{V}_{\mathrm{p}}\right)$ in the tilted $\mathrm{Bi}_{2} \mathrm{Sr}_{2} \mathrm{Co}_{2} \mathrm{O}_{\mathrm{y}}$ thin film on the $308 \mathrm{~nm}$ laser energy on the film surface. A linear dependence is obtained for laser energy below the destruction limit of the film. The dependence of the LIV signal of the tilted $\mathrm{Bi}_{2} \mathrm{Sr}_{2} \mathrm{Co}_{2} \mathrm{O}_{y}$ film on the tilted angle $\alpha$ is also investigated and an almost linear relationship between the $V_{p}$ value and $\alpha$ is obtained, seen in Fig. 5b. This Uøsin $2 \alpha$ dependence again demonstrates that the LIV effect in the $c$ axis tilted layered cobalt oxides thin films mainly originates from the transverse thermoelectric effect since all other light-induced effects do not shown such tilt angle dependence.

Fig. 5c presents $V_{p}$ as a function of the film thickness under $308 \mathrm{~nm}$ laser radiation. The $V_{P}$ increases with the decrease of film thickness and reaches a maximum value when the film thickness is about $100 \mathrm{~nm}$, and then $V_{p}$ turns to a reduction with further decreasing film thickness from $100 \mathrm{~nm}$ to $60 \mathrm{~nm}$. This is inconsistent with Eq. (1) where $V_{p}$ increases monotonically with decreasing $d$. Similar $V_{p}-d$ dependence was observed in the LIV measurements for $c$-axis tilted YBCO and LCMO films. An improved equation based on the plane heat source and cascade power net model was proposed to explain this abnormal behavior. Calculations based on this improved equation revealed that $V_{p}$ was no more monotonic variation with the thickness $d$ and there existed an optimum thickness corresponding to a maximum peak of the induced signal [9]. 

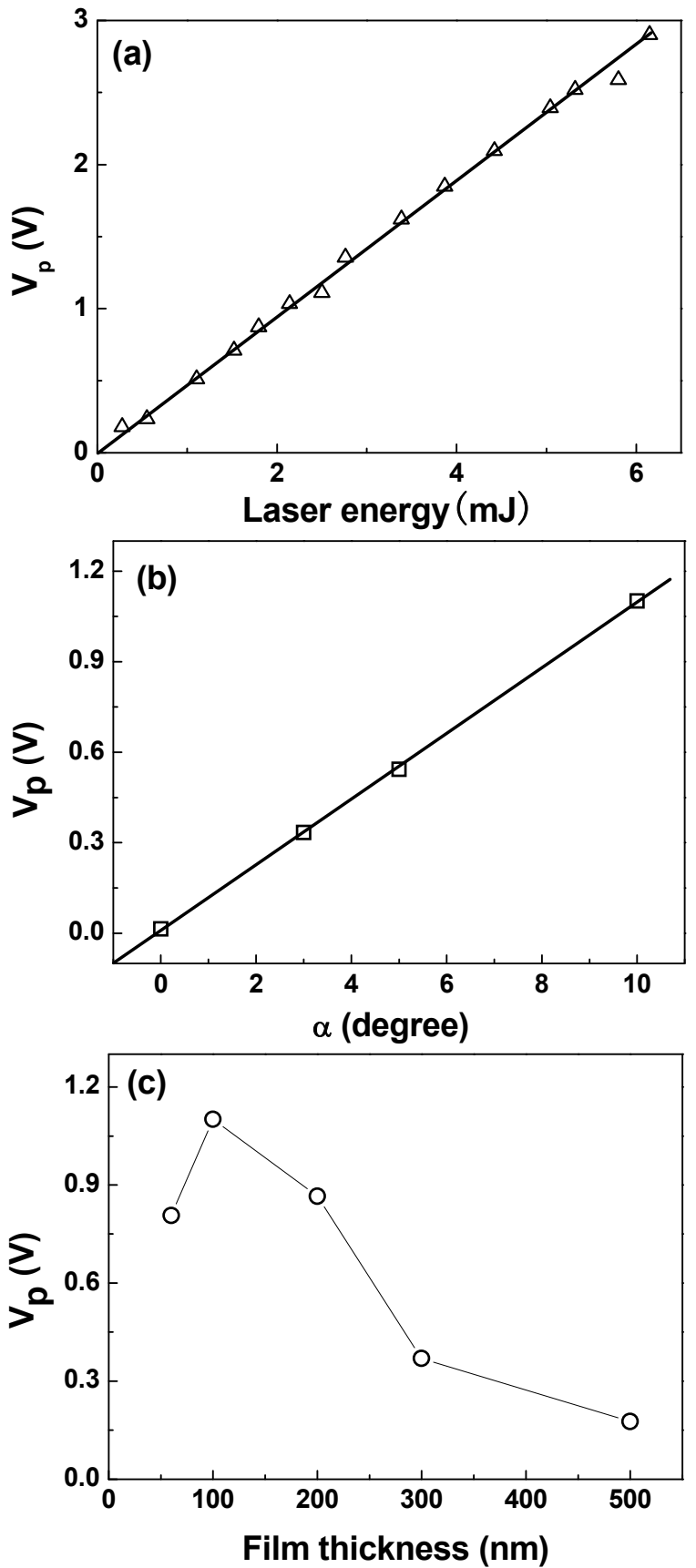

Fig. 5. Dependence of the peak value of the induced open-circuit voltage $\left(\mathrm{V}_{\mathrm{p}}\right)$ on the (a) laser energy on the film surface, (b) tilted angle $\alpha$ and (c) film thickness. Solid lines are guide for eyes. 


\subsection{LIV signal in C-axis $\mathrm{Ca}_{3} \mathrm{Co}_{4} \mathrm{O}_{9}$ and $\mathrm{Na}_{\mathrm{x}} \mathrm{CoO}_{2}$ thin films}

Similar results are also observed in the $c$-axis tilted $\mathrm{Ca}_{3} \mathrm{Co}_{4} \mathrm{O}_{9}$ thin films when their surface is irradiated by the above lasers. Fig. 6 presents a typical laser-induced open-circuit voltage signal of the $10^{\circ}$ tilted $\mathrm{Ca}_{3} \mathrm{Co}_{4} \mathrm{O}_{9}$ thin film $(\sim 100 \mathrm{~nm})$ under the $308 \mathrm{~nm}$ pulsed illumination with the laser energy on the sample of $1 \mathrm{~mJ}$. Both the responsivity $(\sim 230 \mathrm{mV} / \mathrm{mJ})$ and the response time (the rise time $\sim 60 \mathrm{~ns}$ and the FWHM 700 ns) of the LIV signal in this tilted $\mathrm{Ca}_{3} \mathrm{Co}_{4} \mathrm{O}_{9}$ thin film is in the same order as that of the tilted $\mathrm{Bi}_{2} \mathrm{Sr}_{2} \mathrm{Co}_{2} \mathrm{O}_{\mathrm{y}}$ thin film with the same thickness.

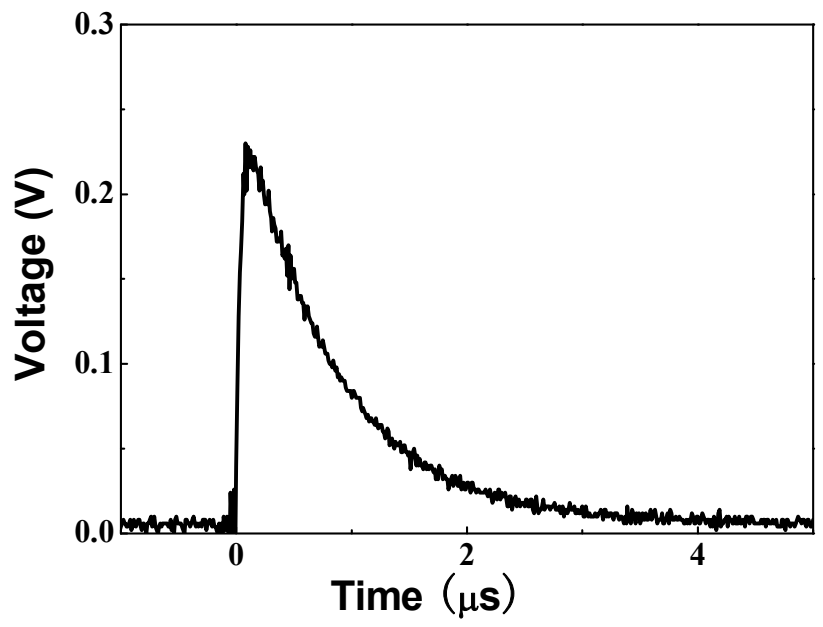

Fig. 6. A typical LIV signal of a $10^{\circ} \mathrm{c}$-axis tilted $\mathrm{Ca}_{3} \mathrm{Co}_{4} \mathrm{O}_{9}$ thin film $(\sim 100 \mathrm{~nm})$ under the 308 $\mathrm{nm}$ laser radiation. The laser energy on the sample is about $1 \mathrm{~mJ}$.

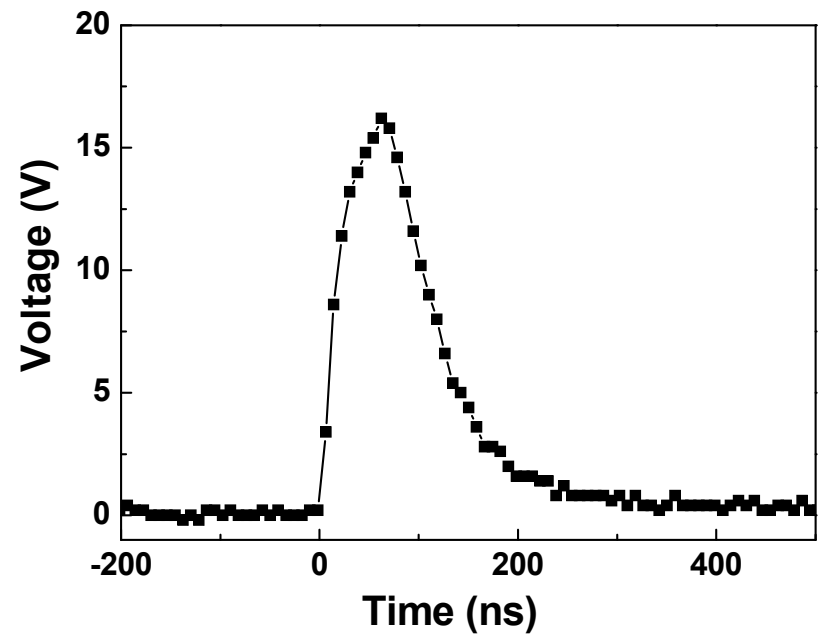

Fig. 7. A typical LIV signal of a $10^{\circ} \mathrm{c}$-axis tilted $\mathrm{Na}_{x} \mathrm{CoO}_{2}$ thin film $(\sim 140 \mathrm{~nm})$ under the 308 $\mathrm{nm}$ laser radiation. The laser energy on the sample is about $1.5 \mathrm{~mJ}$. 
The performed LIV measurements on the $c$-axis tilted $\mathrm{Na}_{x} \mathrm{CoO}_{2}$ thin films show similar dependence of $\mathrm{V}_{\mathrm{p}}$ on the laser energy, tilted angle $\alpha$ and film thickness. However, the $c$-axis tilted $\mathrm{Na}_{x} \mathrm{CoO}_{2}$ thin films have a much larger induced voltage signal than that of the $\mathrm{Bi}_{2} \mathrm{Sr}_{2} \mathrm{Co}_{2} \mathrm{O}_{\mathrm{y}}$ and $\mathrm{Ca}_{3} \mathrm{Co}_{4} \mathrm{O}_{9}$ thin films. Fig. 7 illustrates the laser-induced open-circuit voltage signal of the $10^{\circ}$ tilted $\mathrm{Na}_{x} \mathrm{CoO}_{2}$ film irradiated by the $308 \mathrm{~nm}$ pulsed laser with the laser energy on the sample of $1.5 \mathrm{~mJ}$. A giant open-circuit voltage signal with $\mathrm{V}_{\mathrm{p}}$ of $16.3 \mathrm{~V}$ is observed. The responsivity is calculated to be about $11 \mathrm{~V} / \mathrm{mJ}$. It is much larger than the responsivity of YBCO, LCMO and other two cobalt oxide thin films [1-4, 18, 19]. This might be due to the $\mathrm{Na}_{x} \mathrm{CoO}_{2}$ film has better crystal quality which corresponds to a larger $\Delta S$, and the exact reason needs to be clarified in our future work.

\section{Conclusion}

In conclusion, the performed investigations of the LIV effect in $c$-axis tilted $\mathrm{Na}_{x} \mathrm{CoO}_{2}$, $\mathrm{Bi}_{2} \mathrm{Sr}_{2} \mathrm{Co}_{2} \mathrm{O}_{y}$ and $\mathrm{Ca}_{3} \mathrm{Co}_{4} \mathrm{O}_{9}$ thin films at room temperature show that large open-circuit lateral voltage signals with the rise time in the order of several nanoseconds are measured when the surface of these films is irradiated by different laser sources with the wavelength ranging from UV to NIR. The obtained results suggest that $c$-axis tilted cobalt oxide thin films can be used for broadband photodetectors with fast response.

\section{Acknowledgments}

This work was partially supported by NSFC of China under Grant No. 10904030, SFC of Hebei Province under Grant No. A2009000144 and E 2006001006.

\section{References}

[1] H. Lengfellner, G. Kremb, A. Schnellbbgl, J. Betz, K. F. Renk, W. Prettl, Appl. Phys. Lett. 60, 601(1992)

[2] S. Zeuner, W. Prettl, H. Lengfellner, Appl. Phys. Lett. 66, 1833 (1995)

[3] Th. Zahner, R. Stierstorfer, S. Reindl, T. Schauer, A. Penzkofer, H. Lengfellner, Physica C 313, 37(1999)

[4] P.X. Zhang, W.K. Lee, G.Y. Zhang, Appl. Phys. Lett. 81, 4026(2002)

[5] H.-U. Habermeiera, X.H. Li, P.X. Zhang, B. Leibold, Sol. State Commun. 110, 473(1999)

[6] K. Zhao, M. He, G.Z. Liu, H.B. Lu, J. Phys. D: Appl. Phys. 40, 5703(2007)

[7] S. Zeuner, H. Lengfellner, W. Prettl, Phy. Rev. B 51, 11903 (1995)

[8] H. Lengfellner, S. Zeuner, W. Prettl, K. F. Renk, Europhys. Lett. 25, 375 (1994)

[9] P.X. Zhang and H.-U. Habermeier, J. Nanometers 2008, 329601 (2008)

[10] I. Terasaki, Y. Sasago, K. Uchinokura, Phys. Rev. B 56, R12685(1997)

[11] Y.Y. Wang, N.S. Rogado, R.J. Cava, N.P. Ong, Nature (London) 423, 425 (2003)

[12] M. Shikanoa, R. Funahashi, Appl. Phys. Lett. 82, 1857(2003)

[13] R. Funahashia, M. Shikano, Appl. Phys. Lett. 81, 1459(2001)

[14] K. Koumoto, I. Terasaki, R. Funahashi, MRS Bulletin 31, 206 (2006)

[15] S.F. Wang, Z.C. Zhang, L.P. He, M.J. Chen, W. Yu, G.S. Fu, Appl. Phys. Lett. 94, 162108 (2009)

[16] S.F. Wang, A. Venimadhav, S.M. Guo, K. Chen, X. X. Xi, Appl. Phys. Lett. 94, 022110 (2009) 
[17] S.F. Wang, M.J. Cheng, L.P. He, W. Yu, G.S. Fu, J. Phys. D: Appl. Phys. 42, 045410 (2009)

[18] S.F. Wang, J.C. Chen, X.H. Zhao, S.Q. Zhao, L.P. He, M.J. Chen, W. Yu, J.L. Wang, G.S. Fu, Appl. Sur. Sci. 257, 157(2010)

[19] S.F. Wang, J.C. Chen, S.R. Zhao, L.P. He, M.J. Chen, W. Yu, J.L. Wang, G.S. Fu, Chin. Phys. B 19, 107201 (2010) 


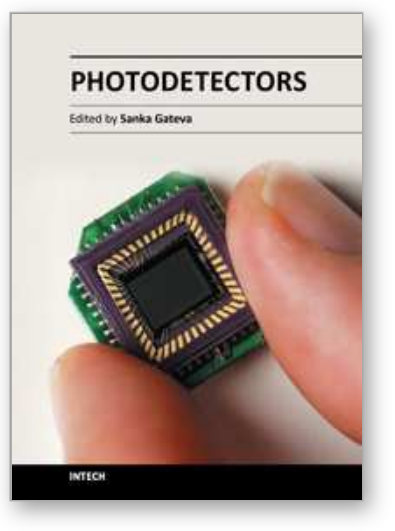

\author{
Photodetectors \\ Edited by Dr. Sanka Gateva
}

ISBN 978-953-51-0358-5

Hard cover, 460 pages

Publisher InTech

Published online 23, March, 2012

Published in print edition March, 2012

In this book some recent advances in development of photodetectors and photodetection systems for specific applications are included. In the first section of the book nine different types of photodetectors and their characteristics are presented. Next, some theoretical aspects and simulations are discussed. The last eight chapters are devoted to the development of photodetection systems for imaging, particle size analysis, transfers of time, measurement of vibrations, magnetic field, polarization of light, and particle energy. The book is addressed to students, engineers, and researchers working in the field of photonics and advanced technologies.

\title{
How to reference
}

In order to correctly reference this scholarly work, feel free to copy and paste the following:

Shufang Wang and Guangsheng Fu (2012). Broadband Photodetectors Based on c-Axis Tilted Layered Cobalt Oxide Thin Films, Photodetectors, Dr. Sanka Gateva (Ed.), ISBN: 978-953-51-0358-5, InTech, Available from: http://www.intechopen.com/books/photodetectors/broadband-photodetectors-based-on-c-axis-tilted-layeredcobalt-oxide-thin-films-

\section{INTECH}

open science | open minds

\section{InTech Europe}

University Campus STeP Ri Slavka Krautzeka 83/A 51000 Rijeka, Croatia Phone: +385 (51) 770447

Fax: +385 (51) 686166 www.intechopen.com

\section{InTech China}

Unit 405, Office Block, Hotel Equatorial Shanghai No.65, Yan An Road (West), Shanghai, 200040, China 中国上海市延安西路65号上海国际贵都大饭店办公楼405单元 Phone: +86-21-62489820

Fax: +86-21-62489821 
(C) 2012 The Author(s). Licensee IntechOpen. This is an open access article distributed under the terms of the Creative Commons Attribution 3.0 License, which permits unrestricted use, distribution, and reproduction in any medium, provided the original work is properly cited. 